\title{
Heats of Combustion and Formation of Liquid Ethylenimine
}

\author{
Raymond A. Nelson and Ralph S. Jessup
}

\begin{abstract}
The heat of combustion of ethylenimine was measured at $28^{\circ} \mathrm{C}$ in a bomb calorimeter. The experimental data yielded the value $-\Delta H_{c}^{\circ}=1591.36 \pm 0.57$ kilojoules per mole for the heat of combustion at $25^{\circ} \mathrm{C}$, the reactants being liquid ethylenimine and gaseous oxygen and the products being gaseous carbon dioxide, gaseous nitrogen, and liquid water. By combining this value with data on the heats of formation of gaseous carbon dioxide and liquid water, the value $\Delta H_{f}^{\circ}=91.90 \pm 0.59$ kilojoules per mole was obtained for the heat of formation of liquid ethylenimine at $25^{\circ} \mathrm{C}$.
\end{abstract}

\section{Introduction}

No data on the heats of combustion and formation of ethylenimine have been found in the literature. This paper describes measurements of the heat of combustion of the liquid by means of a bomb calorimeter. The result of these measurements was combined with values for the heats of formation of gaseous carbon dioxide and liquid water to obtain a value for the heat of formation of liquid ethylenimine.

\section{Material}

The ethylenimine used in this investigation had been purified by triple distillation, and was believed by the manufacturer to be about 99.9 percent pure, the most likely impurities being water and polymerization products [1]. ${ }^{1}$ This estimate was based on the fact that the temperature range during the third distillation was zero within the precision of the measurement $( \pm 0.1 \mathrm{deg} C)$. No further test of purity was made. The results of determining the amount of carbon dioxide formed in combustion of weighed samples of the liquid (see section 5) indicated that inert impurity probably amounted to about 0.07 percent. Inert impurity would have no appreciable effect on the results reported.

The material was received in sealed glass bulbs, each containing about $5 \mathrm{~g}$ of liquid and a pellet of sodium hydroxide to absorb any carbon dioxide that might be present. According to [2], ethylenimine will keep indefinitely if carbon dioxide is excluded.

Samples of about $1 \mathrm{~g}$ each of ethylenimine were prepared for combustion in the bomb by sealing them in thin-walled glass bulbs, which were flattened on opposite sides and filled completely with the liquid $[3,4,5]$. In preparation for filling these bulbs, a container in which the ethylenimine was received was opened and the contents poured into a small beaker that contained a pellet of sodium hydroxide. The stems of several weighed glass bulbs were then immersed in the liquid in this beaker, and the whole apparatus was placed in a vacuum desiccator. The bulbs were filled by alternately reducing the pressure in the desiccator and admitting air to bring the pressure back to atmospheric. The air admitted

\footnotetext{
1 Figures in brackets indicate the literature references at the end of this paper.
}

during this process was passed through an absorption tube containing Ascarite to remove carbon dioxide. Because of the high volatility of ethylenimine, the bulbs were filled completely by this process, and it was not necessary to heat them to expel the last traces of air, as would be the case for a much less volatile liquid.

After the bulbs (and stems) were completely filled, the liquid was partially removed from the stems by heating these stems and boiling out a part of the liquid. The remainder of the liquid in each stem was then drawn into the bulb by cooling the bulb with ice, and the stem was removed by sealing off near the bulb with a hot flame. It was observed that the part of each stem that was heated to boil out the liquid was slightly discolored, either by decomposition products or by etching of the glass. No such effect was observed, however, in the neighborhood of the point at which the stem was sealed off from the bulb, and no evidence of decomposition of the liquid in the bulb was observed.

\section{Apparatus and Method}

The calorimeter system and the experimental procedure have been described previously [4, 6, 7]. The bomb used was made of illium and had a capacity of $381 \mathrm{ml}$. One milliliter of water was placed in the bomb before each experiment. The experimental results are referred to a reaction temperature of $28^{\circ} \mathrm{C}$.

The mass of the sample burned was determined by weighing, and the mass of carbon dioxide formed in the combustion was determined by absorbing it in Ascarite and weighing. The apparatus used for the absorption of the carbon dioxide is similar to that described by Prosen and Rossini [8], except that no provision was made to oxidize the products of incomplete combustion and absorb the resulting carbon dioxide. Instead, a test for carbon monoxide was made on the gaseous products of each experiment after the carbon dioxide had been absorbed, using a colorimetric method developed at the Bureau [9]. In every case where carbon monoxide was found, unburned carbon was also found in the bomb and the experiment was discarded. The results reported in section 5 are all based upon determination of the amount of the reaction from the mass of carbon dioxide formed in combustion. 
The observed heat of combustion in each experiment was corrected for heat of stirring and heat transfer between calorimeter and surroundings, for the energy used to ignite the charge, and for the energy produced by the formation of nitric acid in the bomb. A value of $59.2 \mathrm{kj} /$ mole [11] was used in correcting for the formation (at $28^{\circ} \mathrm{C}$ ) of aqueous nitric acid (about 0.25 molar) during the combustion. This correction amounted, on the average, to 0.37 percent of the total heat produced by the combustion. The nitrogen in the nitric acid represented about 10 percent of the total nitrogen in the sample.

It was assumed that all the oxidized nitrogen in the bomb was completely converted to nitric acid. Tests for the presence of fixed nitrogen in the bomb gases were made by passing the gases through a scrubbing column containing a sodium hydroxide solution and testing this solution for the presence of nitrites and nitrates. No indication of sodium nitrite or sodium nitrate in this solution was found by tests sensitive to $0.01 \mathrm{mg}$ of either.

The observed heat of combustion, $-\Delta U_{B}$, under the conditions of the bomb process in each experiment was reduced to the value of $-\Delta U_{c}^{\circ}$, the decrease in intrinsic energy accompanying the reaction

$$
\mathrm{C}_{2} \mathrm{H}_{5} \mathrm{~N}(\mathrm{liq})+\frac{13}{4} \mathrm{O}_{2}(\mathrm{~g})=2 \mathrm{CO}_{2}(\mathrm{~g})+\frac{1}{2} \mathrm{~N}_{2}(\mathrm{~g})+\frac{5}{2} \mathrm{H}_{2} \mathrm{O}(\mathrm{liq})
$$

with each of the reactants and products in its thermodynamic standard state. This was done in accordance with the Washburn procedure [10], modified so as to apply to $28^{\circ} \mathrm{C}$ and to the energy content of the gases at zero pressure instead of $1 \mathrm{~atm}$.

The measurements were made in terms of the absolute joule as the unit of energy. Conversion to the conventional thermochemical calorie was made by use of the relation $1 \mathrm{cal}=4.1840$ abs $\mathrm{j}$.

\section{Calibration of Calorimeter}

The calorimeter was calibrated with NBS standard Sample $39 \mathrm{~g}$ of benzoic acid, using for the heat of combustion of this material the value 26433.8 abs $\mathrm{j} / \mathrm{g}$ under the standard conditions of the bomb process. The mean of the results of seven calibration experiments covering the temperature range $25.1^{\circ}$ to $28.0^{\circ} \mathrm{C}$ is $13933.1 \mathrm{j} / \mathrm{deg} \mathrm{C}$, and the standard deviation of this mean value is $\pm 1.0 \mathrm{j} / \mathrm{deg} \mathrm{C}$.

\section{Results}

The results of measurements of the heat of combustion are given in table 1 , where $-\Delta U_{B}$ is the observed heat of combustion under the conditions specified by the volume of the bomb (0.381 liter), the mass $(1 \mathrm{~g})$ of water placed in the bomb at the beginning of each experiment, the temperature $\left(28^{\circ} \mathrm{C}\right)$ to which the combustion reaction is referred, and the data given in columns 1 and 2 of the table; and where $-\Delta U_{c}^{\circ}$ represents the decrease in intrinsic energy accompanying reaction (1) when the react- ants and produces are all in their thermodynamic standard states at $28^{\circ} \mathrm{C}$.

TABLE 1. Summary of experimental data

\begin{tabular}{|c|c|c|c|c|}
\hline \multirow{2}{*}{$\begin{array}{l}\text { Mass of } \\
\text { sample }\end{array}$} & \multirow{2}{*}{$\begin{array}{l}\text { Initial } \mathrm{O}_{2} \\
\text { pressure at } \\
\quad 28^{\circ} \mathrm{C}\end{array}$} & \multirow{2}{*}{ Mass of $\mathrm{CO}_{2}$} & \multicolumn{2}{|c|}{ Energy of combustion at $28^{\circ} \mathrm{C}$} \\
\hline & & & $-\Delta U_{B}$ & $-\Delta U_{c}^{\circ}$ \\
\hline $\begin{array}{c}g \\
0.86016 \\
1.10140 \\
0.90841 \\
.92242 \\
.80004 \\
.87768\end{array}$ & $\begin{array}{l}\text { atm } \\
32.4 \\
32.7 \\
32.0 \\
31.2 \\
33.0 \\
32.1\end{array}$ & $\begin{array}{c}g \\
\text { 1. } 75745 \\
2.24969 \\
1.85411 \\
1.88515 \\
1.63451 \\
1.79121\end{array}$ & $\begin{array}{l}j / g \mathrm{CO}_{2} \\
18072.4 \\
18081.1 \\
18092.6 \\
18079.4 \\
18092.1 \\
18087.7\end{array}$ & $\begin{array}{c}j / g \mathrm{CO}_{2} \\
18067.8 \\
18076.0 \\
18087.9 \\
18074.8 \\
18087.5 \\
18083.1\end{array}$ \\
\hline & \multicolumn{2}{|c|}{ Standard deviation of mea } & $\begin{array}{l}\text { Mean } \\
\text { n }\end{array}$ & $\begin{array}{l}18079.5 \\
\quad \pm 3.3(0.018 \%)\end{array}$ \\
\hline
\end{tabular}

The values obtained for the mass of carbon dioxide formed in combustion, which is taken as the measure of the amount of the reaction, are lower than the corresponding values calculated stoichiometrically from the mass of the sample burned on the basis that the sample is all $\mathrm{C}_{2} \mathrm{H}_{5} \mathrm{~N}$. The average difference between observed and calculated mass of carbon dioxide is 0.07 percent. The carbon dioxide absorption apparatus was checked before and after this work with Standard Sample $39 \mathrm{~g}$ of benzoic acid and found to yield experimental results that checked the calculated values to better than 0.01 percent. No evidence of incomplete combustion was found in any of the experiments listed in table 1 . It was assumed that the difference between the observed and calculated masses of carbon dioxide when ethylenimine was burned was due to inert impurity, probably dissolved air or water.

In table 2 are given values of heat of combustion and heat of formation per mole of ethylenimine calculated from the mean value reported in table 1 on the basis that 2 moles $(88.020 \mathrm{~g})$ of carbon dioxide corresponds to 1 mole of ethylenimine (eq 1). The value of $-\Delta H_{c}^{\circ}\left(28^{\circ} \mathrm{C}\right)$ was reduced to $25^{\circ} \mathrm{C}$, using the values reported in [13] for the specific heats at constant pressure of carbon dioxide, nitrogen, and oxygen; the value reported in [12] for water; and the estimated value of $2 \mathrm{j} / \mathrm{g} \operatorname{deg} \mathrm{C}$ for the specific heat of liquid ethylenimine. The value of $\Delta H_{f}^{\circ}\left(25^{\circ} \mathrm{C}\right)$ was obtained by combining the value of $-\Delta H_{e}^{\circ}$ $\left(25^{\circ} \mathrm{C}\right)$ with values for the heats of formation of liquid water and gaseous carbon dioxide [11].

TABLE 2. Values of heats of combustion and formation of liquid ethylenimine

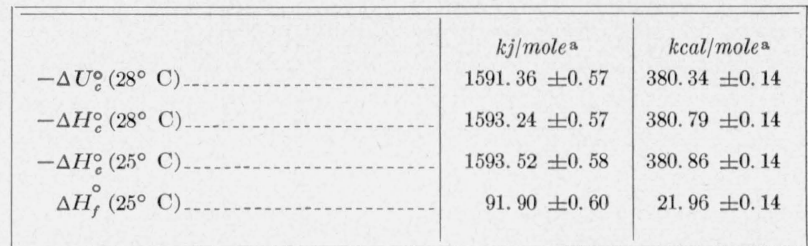

s The numbers following the \pm signs were obtained by appropriately combining the following quantities: (a) The standard deviation of the mean result of the calibration experiments, (b) the standard deviation of the mean value of $-\Delta U_{c}^{\circ}$ for ethylenimine, (c) an estimate $(0.005 \%)$ of the standard deviation of the value used for the heat of combustion of benzoic acid, and (d) an allowance of $0.03 \%$ for the effect of impurities in the ethylenimine. For the heat of formation, allowance of carbon dioxide and water. 
Calculation of the amount of the combustion reaction on the basis of the mass of carbon dioxide produced is equivalent to assuming that the sample was composed entirely of $\mathrm{C}_{2} \mathrm{H}_{5} \mathrm{~N}$ and inert impurity. The effect of such inert impurities is thus completely eliminated. There remains, however, the possibility of a slight systematic error from polymers of ethylenimine or other combustible impurities that may have been present.

\section{Strain Energy}

It is of interest to compare the experimental value of the heat of formation of ethylenimine with a value calculated from bond energies, as the difference between the two may be considered as an approximation to the strain energy of the molecule. For this purpose the heat of vaporization of ethylenimine was estimated to be about $4 \mathrm{kcal} / \mathrm{mole}$, making the heat of formation of the gas about $26 \mathrm{kcal} / \mathrm{mole}$. Bond energies at $298^{\circ} \mathrm{C}$ were taken from a table prepared by C. W. Beckett [14]. These bond energies were calculated from values of heats of formation, following essentially the same procedure as Pauling [19], Pitzer [20], and others [21]. The data used were taken from [11], except for the heat of formation of gaseous atomic nitrogen, which was taken from [15].

The value calculated from these bond energies for the heat of formation of gaseous ethylenimine is $12 \mathrm{kcal} / \mathrm{mole}$, so that the corresponding value for the strain energy is $14 \mathrm{kcal} / \mathrm{mole}$.

For comparison, the strain energies of the threemembered ring compounds cyclopropane, ethylene oxide, and ethylene sulfide were calculated in the same manner, and the values obtained are 25,13 , and $9 \mathrm{kcal} / \mathrm{mole}$, respectively. The experimental values used for the heats of formation of these three compounds are those given in [22], [11], and [18], respectively. The above value for the strain energy of cyclopropane is somewhat lower than the values calculated by Kilpatrick and Spitzer [16] (10 to $12 \mathrm{kcal} / \mathrm{CH}_{2}$ unit), and by Coulson and Moffitt [17] $\left(\frac{1}{2}\right.$ to $1 \mathrm{ev} \cong 12$ to $23 \mathrm{kcal} / \mathrm{CH}_{2}$ unit).

The calculation of strain energy from bond energies is subject to relatively large uncertainty, partly because of possible errors in some of the values used for heats of formation, and partly because the calculations are based on the assumption that the energy of a given bond is the same in different compounds. The values of strain energy obtained in the manner indicated may be in error by several kilocalories per mole. Because of these uncertainties, not much significance can be attributed to the differences in the values given above for the strain energies of ethylenimine, ethylene oxide, ethylene sulfide, and cyclopropane.

\section{References}

[1] Hans Osborg, Chemirad Corp., Bladensburg, Md., private communication.

[2] G. D. Jones, A. Langsjoen, M. M. C. Neumann, J Zomlefer, J. Org. Chem. 9, 125 (1944).

[3] T. W. Richards and F. Barry, J. Am. Chem. Soc. 3\%, 993 (1915).

[4] R. S. Jessup, J. Research NBS 18, 115 (1937) RP966.

[5] R. S. Jessup and C. S. Cragoe, National Advisory Committee for Aeronautics, Technical Note No. 996, p. 5 (June 1945).

[6] H. C. Dickinson, Bul. BS 11, 189 (1914) S230.

[7] R. S. Jessup and C. B. Green, J. Research NBS 13, 469 (1934) RP721.

[8] E. J. R. Prosen and F. D. Rossini, J. Reaserch NBS 27, 289 (1941) RP1420.

[9] M. Shepherd, Anal. Chem. 19, 77 (1947)

[10] E. W. Washburn, BS J. Research 10, 525 (1933) RP546.

[11] Selected values of chemical thermodynamic properties, NBS Circular 500 (1952).

[12] N. S. Osborne, H. F. Stimson, D. C. Ginnings, J. Research NBS 23, 197 (1939) RP1228

[13] NBS-NACA Tables of thermal properties of gases, Table 9.10, Oxygen (July 1949); Table 11.10, Nitrogen (July 1950); Table 13.10, Carbon dioxide (July 1950).

[14] C. W. Beckett, NBS, private communication.

[15] A. G. Gaydon, Dissociation energies and spectra of diatomic molecules (John Wiley \& Sons, Inc., New York, N. Y., 1947).

[16] John E. Kilpatrick and Ralph Spitzer, J. Chem. Phys. 14, 463 (1946)

[17] C. A. Coulson and W. E. Moffitt, Phil. Mag. 40, 1 (1949).

[18] Stig Sunner, Studies in combustion calorimetry applied to organosulfur compounds, p. 79, Dissertation (Lund, Sweden, 1949).

[19] L. Pauling, The nature of the chemical bond (Cornell Univ. Press, 1939).

[20] K. S. Pitzer, J. Am. Chem. Soc. 70, 2140 (1948).

[21] J. Stamworth, Physical properties of glass (Oxford, Clarendon Press, 1950).

[22] John W. Knowlton and Frederick D. Rossini, J. Research NBS 43, 13 (1949) RP2012.

Washington, May 14, 1951. 